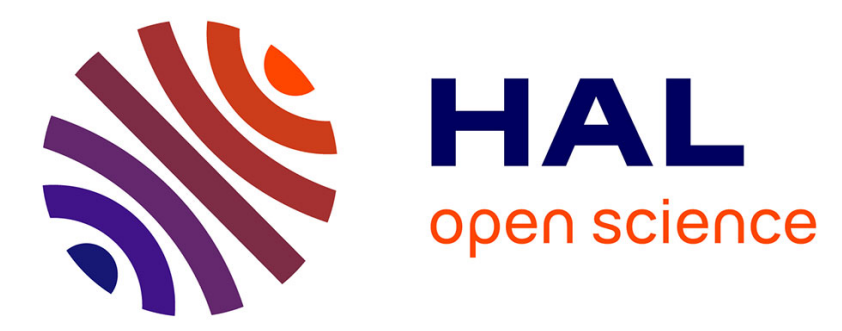

\title{
Investigation by Mössbauer spectroscopy and small angle neutron scattering of the precipitation process in Fe76 Mn12.5 Co8.5 Mo3
}

C. Servant, C. Djega-Mariadassou

\section{- To cite this version:}

C. Servant, C. Djega-Mariadassou. Investigation by Mössbauer spectroscopy and small angle neutron scattering of the precipitation process in Fe76 Mn12.5 Co8.5 Mo3. Journal de Physique IV Proceedings, 1992, 02 (C3), pp.C3-119-C3-126. 10.1051/jp4:1992318 . jpa-00251523

HAL Id: jpa-00251523

https://hal.science/jpa-00251523

Submitted on 1 Jan 1992

HAL is a multi-disciplinary open access archive for the deposit and dissemination of scientific research documents, whether they are published or not. The documents may come from teaching and research institutions in France or abroad, or from public or private research centers.
L'archive ouverte pluridisciplinaire HAL, est destinée au dépôt et à la diffusion de documents scientifiques de niveau recherche, publiés ou non, émanant des établissements d'enseignement et de recherche français ou étrangers, des laboratoires publics ou privés. 


\title{
Investigation by Mössbauer spectroscopy and small angle neutron scattering of the precipitation process in $\mathrm{Fe}_{76} \mathrm{Mn}_{12.5} \mathrm{Co}_{8.5} \mathrm{Mo}_{3}$
}

\author{
C. SERVANT and C. DJEGA-MARIADASSOU*
}

Laboratoire de Métallurgie Structurale, URA CNRS 1107, Bât. 414, Université Paris-Sud, 91405 Orsay cedex, France

"Laboratoire de Structure des Matériaux Métalliques, Bat. 413-414, Université Paris-Sud, 91405 Orsay cedex, France

\begin{abstract}
Additional informations to microhardiness tests, small angle neutron scattering experiments and transmission electron microscopy observations have been obtained by Mössbauer spectroscopy about the various precipitation steps occurring during $700 \mathrm{~K}$ ageing of a model maraging alloy 76-Fe 12.5-Mn 8.5-Co 3.-Mo (\% at). Up to $128 \mathrm{~h}$, three stages are revealed both by the hyperfine parameter perturbations of the b.c.c. matrix and the precipitate behaviour. The results are discussed in correlation with those from the other techniques.
\end{abstract}

\section{Introduction}

The aim of the present work devoted to a model maraging alloy $\mathrm{Fe}_{76} \mathrm{Mn}_{12.5} \mathrm{Co}_{8.5} \mathrm{MO}_{3}$ (\% at) is to obtain further informations by Mössbauer spectroscopy and small angle neutron scattering (SANS) about the various precipitation steps occurring during ageing.

Up to 128 hour ageing duration at $700 \mathrm{~K}$, two main steps had been previously deduced from microhardness measurements for temperatures lower than or equal to $775 \mathrm{~K}(1-2)$. However, the perturbations detected on the Mössbauer spectra reveal modifications in agreement with three precipitation steps which are consistent with SANS experiments. These results will be discussed in conjonction with transmission electron microscopy observations (TEM) and the previous microhardness tests.

\section{Experimental}

The alloy was first elaborated by solid phase sintering process at $1680 \mathrm{~K}$ under hydrogen atmosphere then alternatively cold-rolled to the desired thickness depending on the test performed and homogenized at $1680 \mathrm{~K}$ for two hours and finally quenched to room temperature. They were subsequently aged at $700 \mathrm{~K}$ up to 128 hours. $40 \mu \mathrm{m}$ thick samples were chemically thinned down to $15 \mu \mathrm{m}$ and analyzed in transmission geometry by Mössbauer spectroscopy at room temperature with a $\mathrm{Co}^{57 / R h}$ source. The spectra were computer fitted assuming lorentzian lines with two distinct methods. The first one used several discrete broadened sites while the other, based on the Hess-Rubartsh method gave the matrix hyperfine field distribution (H.F.D.) with a linear correlation between isomer shift $\delta$ and hyperfine field $H$, taking into account the paramagnetic contribution.

SANS experiments were performed on $1 \mathrm{~mm}$ thick samples at the laboratoire Léon Brillouin in Saclay France with a $0.46 \mathrm{~nm}$ and $0.97 \mathrm{~nm}$ wavelength and a two dimensional detector to sample distance equal to $5 \mathrm{~m}$ at $293 \mathrm{~K}$.

TEM measurements were made with a 2000 EX JEOL microscope operating at $200 \mathrm{keV}$. Microhardness tests were carried out with a Leitz-Wetzlar apparatus working under 1 newton load on $1 \mathrm{~mm}$ thick sample. Each data represent a mean value over ten measurements. 


\section{Results}
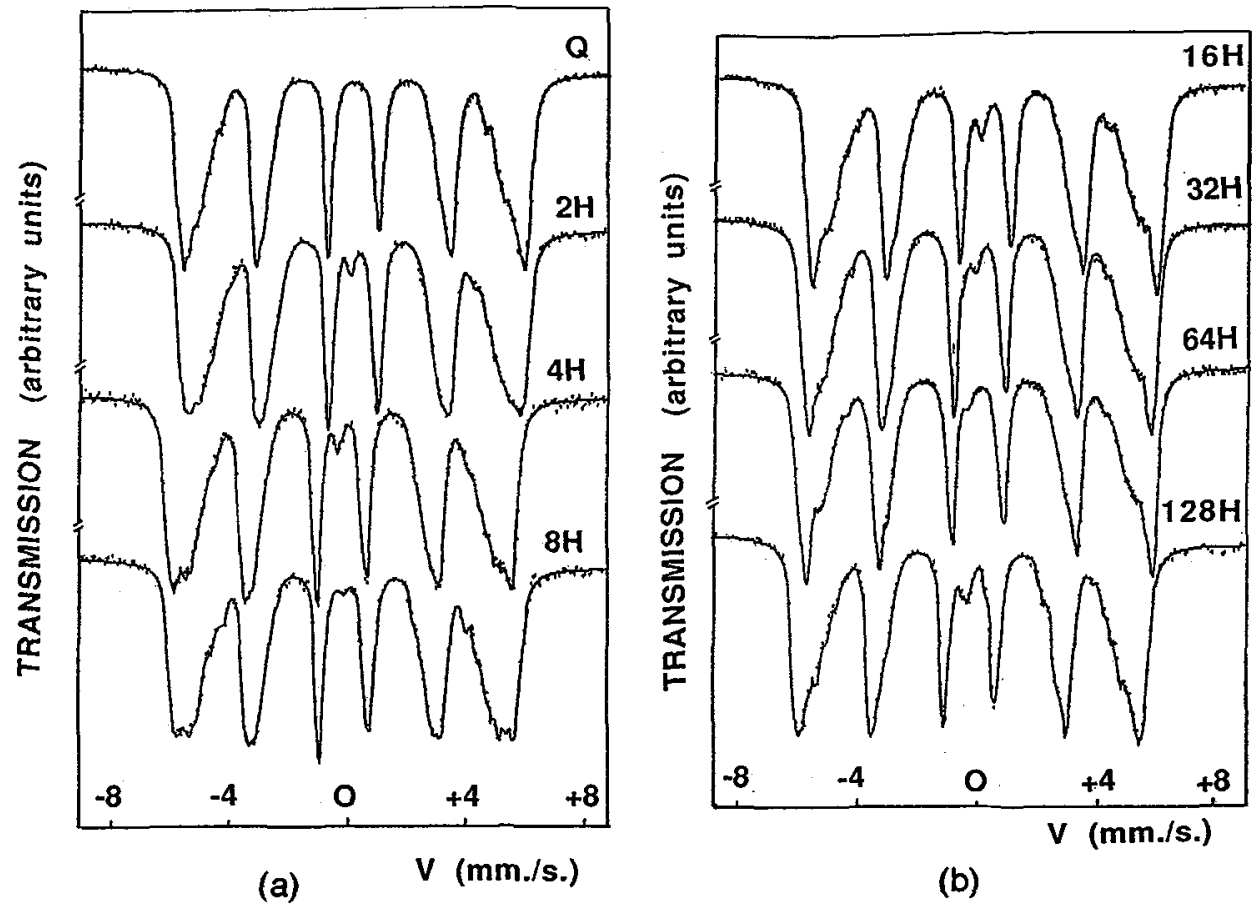

(b)

Fig. 1 Mössbauer spectra at $300 \mathrm{~K}$ for :

a) the as-quenched sample $Q$ and samples aged for 2, 4, 8 hours at $700 \mathrm{~K}$,

b) samples aged for $16,32,64$ and 128 hours at $700 \mathrm{~K}$.

A brief examination of the Mössbauer spectra resulting from the various ageing duration (fig. 1) gives yet evidence for three steps of precipitation revealed both by the precipitate evolutions and by the simultaneous matrix changes.

The first stage up to 8 hours is characterized by a gradual appearence and disappearence of a small paramagnetic line $A$ with an isomer shift variation given in table I. The corresponding matrix first and sixth line shapes are consistent with a continuous range of hyperfine fields. In the second stage, from 16 hours up to 64 hours, the sextet external line profiles are modified and suggest rather two distinct site groups. A new paramagnetic line B appears, characterized by a gradual variation of abondance and isomer shift as a function of ageing duration. For 128 hour ageing, a broadening and an enhancement of the central line attest for the presence of an additionnal paramagnetic line $\mathrm{C}$. Moreover, the matrix magnetic external lines suggest a new field distribution. The associated H.F.D. (fig. 2) and the deduced mean hyperfine field value $\mathrm{H}$ support these observations (Table I).

The microhardness behaviour shows two main steps of precipitation (fig. 3). On figure 4 is reported the longitudinal differential magnetic cross-section $d \sigma / d \Omega$ versus the sattering vector $q$ for increasing time with an applied field of $0.89 \mathrm{~T}$. First, $\mathrm{d} \sigma / \mathrm{d} \Omega$ increases from the as-quenched to the 4 hour aged sample where it goes through a maximum. It then decreases for the 8 hour aged sample down to the quenched state according to the first state of precipitation. Secondly, for the 16 hour aged sample, it slightly increases again, then strongly for the 32 hour aged alloy 

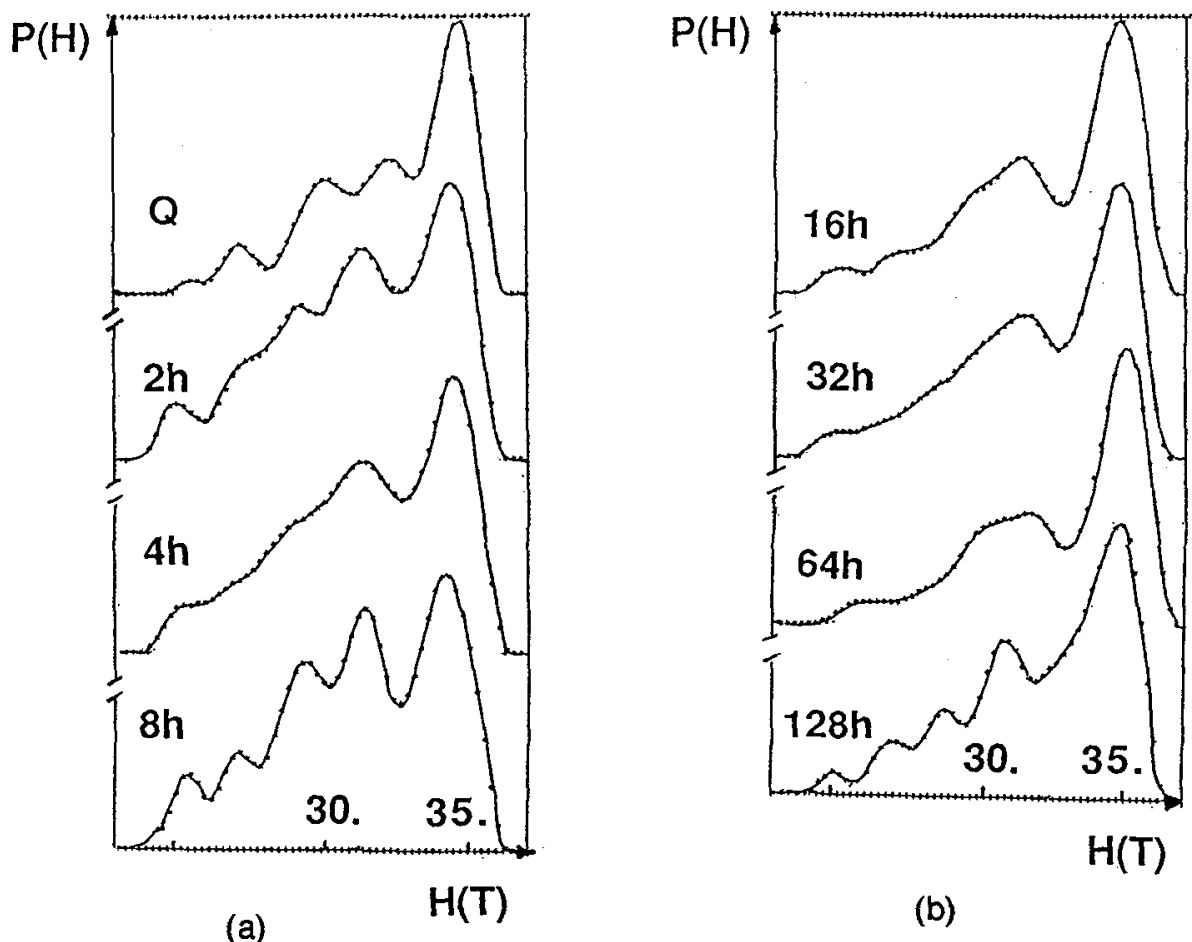

(b)

Fig. 2 Matrix hyperfine field distribution $P(H)$ versus hyperfine field $H$ in Tesla for :

a) the as-quenched sample $Q$ and samples aged for 2, 4, 8 hours at $700 \mathrm{~K}$,

b) samples aged $16,32,64$ and 128 hours at $700 \mathrm{~K}$.

\section{Table I}

Evolution of the precipitate isomer shift $\delta$ and abundance $\alpha$, matrix mean hyperfine field values $\bar{H}$ for the as-quenched sample $Q$ and for various aged samples at $700 \mathrm{~K}$

\begin{tabular}{|c|c|c|c|c|c|c|c|c|}
\hline $\begin{array}{c}\text { ageing duration } \\
\text { (hours) }\end{array}$ & $\mathbf{Q}$ & 2 & 4 & 8 & 16 & 32 & 64 & 128 \\
\hline $\begin{array}{c}\delta(\mathrm{mm} / \mathrm{s}) \\
\pm 0.02\end{array}$ & & -0.07 & -0.13 & -0.10 & -0.13 & -0.15 & -0.28 & $-0.27-0.06$ \\
\hline $\begin{array}{c}\alpha \% \\
\pm \quad 0.02\end{array}$ & & 1.40 & 1.10 & 0.01 & 2.3 & 2.1 & 1.2 & $1.0 \quad 1.5$ \\
\hline $\begin{array}{l}\bar{H}(\mathrm{~T}) \\
\pm 0.2 \\
\end{array}$ & 32.3 & 30.6 & 30.9 & 31.1 & 32.2 & 32.1 & 32.3 & 32.1 \\
\hline
\end{tabular}




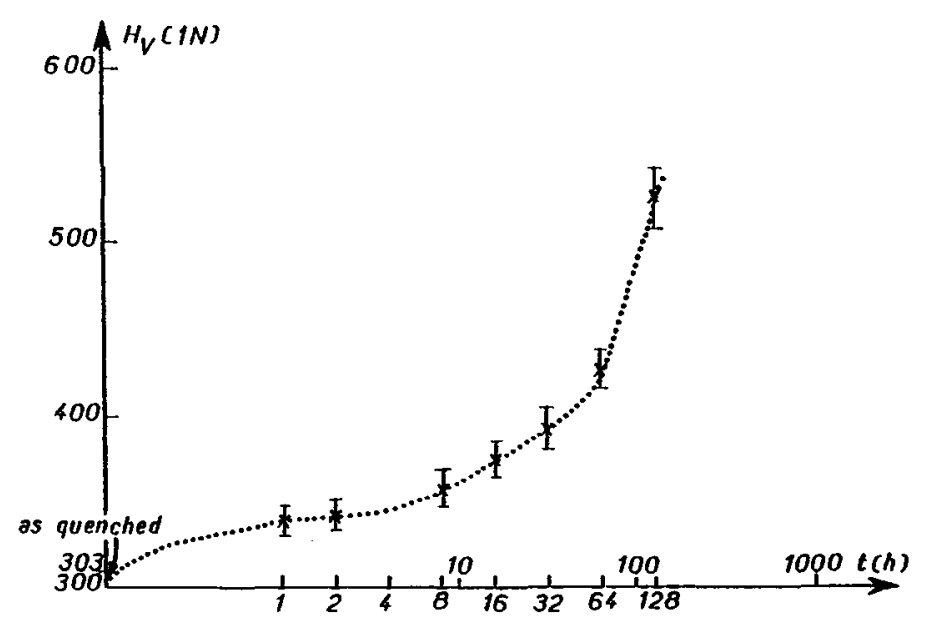

Fig. 3 Vickers microhardness as a function of ageing duration at $700 \mathrm{~K}$.

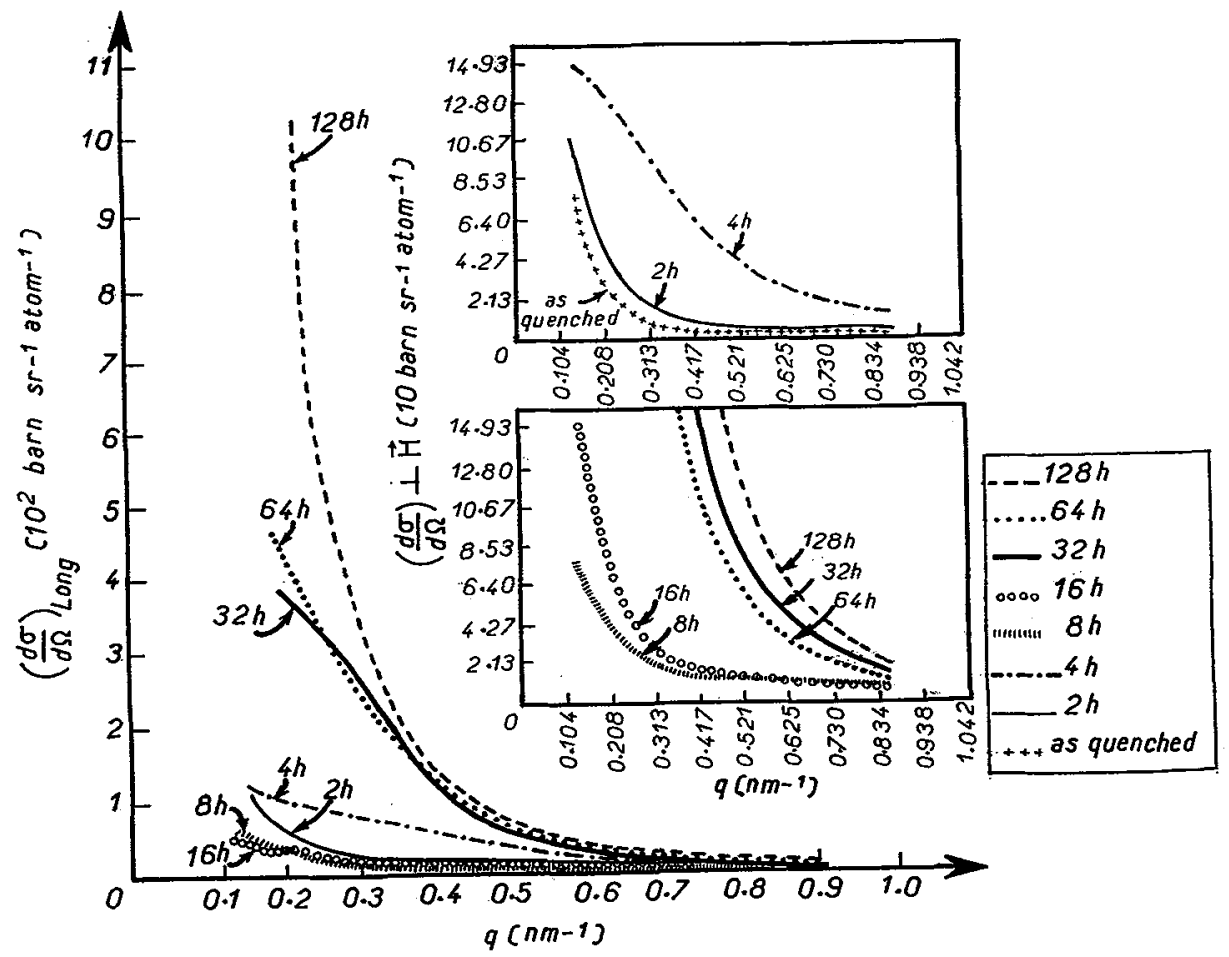

Fig. 4 Longitudinal differential magnetic cross-section $d \sigma / d \Omega$ versus the scattering vector $q$. 
confirming the second stage of precipitation. The vanishing $\mathrm{d} \sigma / \mathrm{d} \Omega$ cross-section for the 64 hour aged alloy outlines the end of the second step. For longer ageing duration (128 h), d $\sigma / d \Omega$ increases giving evidence for a third step of precipitation.

\section{Discussion}

In such b.c.c. disordered alloys, the spectra simulation carried on with discrete enlarged sextets related to the matrix can only be considered as a first stage of interpretation although it can give satisfactory agreement between observed and calculated data. The description of the spectra with the help of a continuous field distribution seems more realistic. However, the interpretation of the H.F.D. with the binomial distribution law needs some assumptions i) the effect of the impurity neighbours is extended to the first and second coordination shells ii) the increment of magnetic fields and isomer shifts at iron atoms due to $\mathrm{Co}, \mathrm{Mn}$, Mo neighbours is based on the values per solute atoms given previously in b.c.c. iron binary alloys : Co enhances the hyperfine field of iron while $\mathrm{Mn}$ and Mo reduce it, the effect of Mo being about twice that of $\mathrm{Mn}(3)$.

In first approximation, it is possible to calculate the H.F.D. in the model of a pseudo-ternary system following the same simplifications that those we made previously in the case of $\mathrm{Ni}$ maraging alloys (4). Co and $\mathrm{Ni}$ induce only a small broadening of iron line-width without resolvable satellites (5).

Figure 5 shows the theoretical probabilities and their associated hyperfine field values calculated in the assumption of a mean $\mathrm{Fe}_{76} \mathrm{C}_{0.5}$ system substituted by $12.5 \mathrm{Mn}$ and $3 \mathrm{Mo}$ atoms. The enhancement of the experimental probability on the quenched sample in the field range $34-35 \mathrm{~T}$ comparatively to the theoretical data demonstrates obviously the presence of heterogeneities in the sample matrix. These heterogeneities can either be assigned to $\mathrm{Fe}-\mathrm{Co}$ areas with a $\mathrm{Fe} / \mathrm{Co}$ ratio around 9/1 surrounded by domains enriched in $M n$ and Mo comparatively to the nominal composition which still remains in other regions. The mean hyperfine field experimental value 32.3 $\mathrm{T}$, too high with regard to the theoretical one $30.7 \mathrm{~T}$ resulting from a statistical distribution of $\mathrm{Fe}, \mathrm{Co}, \mathrm{Mn}$, Mo atoms (fig. 5), corroborates these assertions.

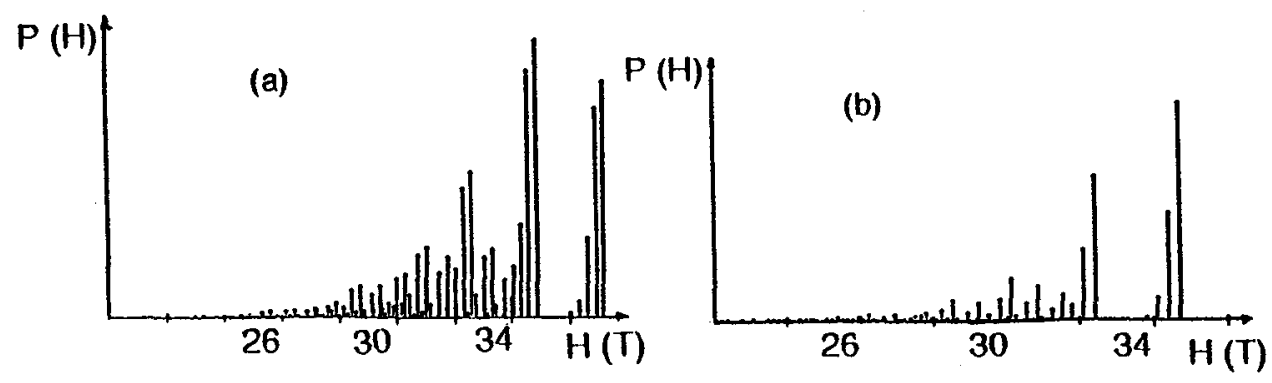

Fig. 5 Theoretical probabilities versus hyperfine field for a statistical distribution of $\mathrm{Co}, \mathrm{Mn}, \mathrm{Mo}$ atoms first and second iron neighbours in the assumption of :

a) the nominal composition $\mathrm{Fe}_{76} \mathrm{Mn}_{12.5} \mathrm{Co}_{8.5} \mathrm{Mo}_{3}$,

b) $\mathrm{Fe}_{81.7} \mathrm{Mn}_{7.4} \mathrm{Cog}_{9.2} \mathrm{Mo}_{1.7}$ formula. 
The H.F.D. exhibits these Fe-Co inhomogeneities for all ageing durations. However, this tendency is less pronounced at the end of the first precipitation step $(8 \mathrm{~h})$ where the probability contribution decreases in the range $35 \mathrm{~T}$. For the second precipitation step from 16 hours up to 64 hours, these Fe-Co heterogeneities reappear and for 128 hour ageing duration, an homogeneization of the matrix occurs.

The A precipitates belonging to the first precipitation stage are not detected by electron microscopy. The reason may be that their volume fraction remains small as suggested by the microhardness behaviour which only increases by 40 Vickers points while for the quenched state, the microhardness was 303 Vickers points (fig. 3). The A precipitates are formed without incubation stage and it comes that the quenched sample displays probably heterogeneities induced by a too slow quenching rate and behaving as $A$ precipitate precursors. This fact can explain that the matrix remains quasi identical between the quenched sample state and the two hour ageing duration one. The A precipitate isomer shift varies gradually, demonstrating a modification of the chemical composition concomitantly to an abundance decrease.

From the Mössbauer spectra, it is not possible to know whether this $\mathrm{Fe}$ contribution decrease results preferentially from a decrease of the volume fraction of the precipitates or from an evolution of their chemical composition. From SANS measurements, the $\mathrm{d} \sigma / \mathrm{d} \Omega$ cross section maximum is observed for 4 hour ageing duration. This apparent discrepancy results from the different sensitivity of both methods. Mössbauer spectroscopy takes into account the iron atomic fraction involved in the precipitates while SANS measurements are concerned with the volume fraction of precipitates and contrast difference between matrix and precipitates. Nevertheless all these results are in agreement with a unique step of precipitation up to 8 hour ageing duration.

The second precipitation step, correlated to the $\mathrm{B}$ precipitates is characterized by a slope change in the microhardness curve which increases clearly up to 64 hour ageing duration.

TEM measurements reveal a phase of Fe2Mo type (fig. 6 a.b.c) which appears from its isomer shift value to be substituted by $\mathrm{Mn}$ or $\mathrm{Co}$. Although the $\delta$ value of the $B$ precipitate for 16 hour ageing duration is very close to the $\delta$ value of the paramagnetic fraction observed on the $4 \mathrm{~h}$ ageing duration spectrum, it is possible to consider that these two precipitates are distinct species. In the first stage of precipitation, for $2 \mathrm{~h}$ ageing duration, TEM measurements do not show any precipitate while on the contrary, the $A$ line abundance is maximum for this ageing duration. Over the second precipitation stage, the $B$ line abundance increases up to 16 hours and its $\delta$ value varies, coming close to that of $\mathrm{Fe}_{2} \mathrm{Mo}$. The neutron diffraction curves for the $32 \mathrm{~h}$ and $64 \mathrm{~h}$ ageing duration sample are quasi identical. This can be explained by the fact that for 64 hours, even if there remains less volume fraction of B precipitates in the sample, their contrast relative to the matrix, for a composition close to $\mathrm{Fe}_{2} \mathrm{Mo}$ is higher than the contrast of the substituted precipitate $\mathrm{Fe}_{2-\mathrm{x}} \mathrm{Co}_{x} \mathrm{MO}_{1-\mathrm{yMn}} \mathrm{Mn}$

The analysis by atom probe on sample aged for 4 hours at $773 \mathrm{~K}$ leads to a composition equal to $\mathrm{Fe}_{46 \pm 4.7} \mathrm{Mn}_{17.7 \pm 3.6} \mathrm{Co}_{0.9 \pm 0.9} \mathrm{Mo}_{35.4 \pm 4.5}$ for the Fe $\mathrm{Fo}_{\mathrm{M}}$ type precipitates supporting the composition tendency observed in the $700 \mathrm{~K}$ aged alloys. It should be also emphasized that the related measured matrix composition Fe81.7 $\pm 0.5 \mathrm{Cog}_{2.2 \pm 0.4} \mathrm{Mn}_{7.4 \pm 0.3} \mathrm{Mo}_{1.7 \pm 0.2}$ gives evidence for Mo ejection. The theoretical probability sequence as a function of the hyperfine field (fig. $5 \mathrm{~b}$ ) exhibits

for such composition maxima in the same field range as the experimental distribution observed in the second precipitation step domain where Fe2Mo type precipitates were revealed. 

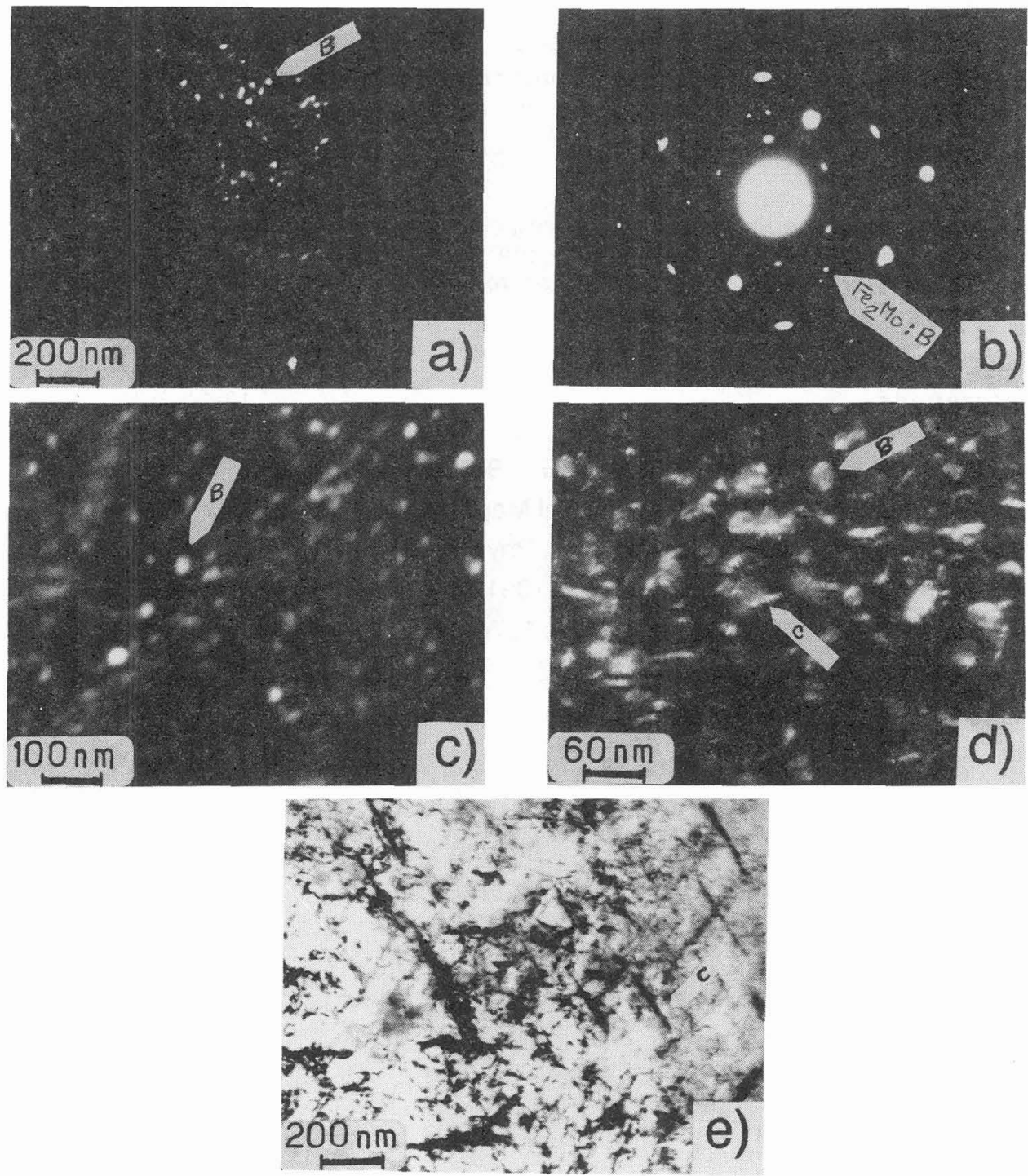

Fig. 6 a) dark field from a spot of $B$ type precipitate ( $32 \mathrm{~h}$ ageing) ;

b) electron diffraction pattern with $\langle 110\rangle_{\text {b.c.c. }}$ zone axis showing supplementary spots assigned to $B$ type precipitate (100 $\mathrm{h}$ ageing) ;

c) dark field from $\mathrm{B}$ spot (100 $\mathrm{h}$ ageing);

d) dark field from $B+C$ type spot (128 $\mathrm{h}$ ageing) (the smallest objective aperture includes the two spots) ;

e) bright field showing $C$ needles (128 $\mathrm{h}$ ageing). 
The 128 hour aged sample shows the onset of the third precipitation step and is characterized by two precipitate species : the B one identical to that of 64 hours $\delta=-0.27 \mathrm{~mm} / \mathrm{s}$ close to Fe $2 \mathrm{Mo}$ and a new one C (Table I) (fig. 6 d.e). Fig. 4 shows that the differential neutron cross section increases drastically.

\section{Conclusion}

Mössbauer spectroscopy has revealed three precipitation steps from the precipitate hyperfine parameters and the matrix hyperfine field distribution in agreement with SANS results. Further experiments should be carried on to elucidate the matrix heterogeneities.

\section{References}

(1) Lecomte J.B., Servant C., Cizeron G., 1985, J. Mater. Sci. 20 - 3339.

(2) C. Servant, N. Bouzid, Philosophical Magazine B, 1989, vol 60, $n^{\circ} 5$ 659-687.

(3) Vincze I. and Campbell I.A., 1973, J. Phys. F - 3 - 647.

(4) Djega-Mariadassou C., Servant C., 1991, Hyp. Int. 69 - 443.

(5) Vincze I., Campbell I.A., Meyer A.J., 1974, 1495 - 1499. 